\title{
Extraction of Trace Cd(II) in Real Samples Using Multi Walled Carbon Nanotubes Carboxylate
}

\author{
HOSSAIN AREFAZAR $^{1 *}$ and ALI MOGHIMI² \\ 1'Department of Physics, South Tehran Branch Islamic Azad University, Tehran, Iran. \\ 2Department of Chemistry, Varamin( Pishva )Branch Islamic Azad University, Varamin, Iran. \\ ${ }^{*}$ Corresponding author E- mail: dharefazar@yahoo.com, alimoghimi@iauvaramin.ac.ir
}

http://dx.doi.org/10.13005/ojc/320523

(Received: July 15, 2016; Accepted: September 23, 2016)

\begin{abstract}
In this method to amounting of the trace little amount of Cd (II) ions in aqueos Samples by CNT carboxyl which in order to improve the performance of extraction and preconcentration was used. Amounting of the ions density in solution was performed by the method of FAAS. The effective parameters on extraction effect of $\mathrm{pH}$, the amount and eluent solvent, time of extraction and effect of other cation were optimized. Concentrate factor was found 30 and LOD method of limit of detection was found to $0.07 \mu \mathrm{g} \cdot \mathrm{L}^{-1}$. The relative standard deviation is $0.79 \%(\mathrm{RSD} \%)$.
\end{abstract}

Keywords: $\mathrm{Cd}(\mathrm{II})$, Preconcentration, Solid phase extraction, MWCNTs-COOH, FAAS.

\section{INTRODUCTION}

The transition metals including $\mathrm{Cd}(\mathrm{II})$ and $\mathrm{Pb}$ (II) etc. are an important risk for humans and animals ${ }^{1-3}$. Also heavy metals at trace levels are components of the natural biosphere. Because the main sources of heavy metals for humans and animals are water, food and atmosphere ${ }^{1,4,5}$ reliable and sensitive analytical methods and procedures have an important role to evaluate the impacts of metal pollutants. The determination of traces metal ions in these samples are continuously performed in the analytical chemistry laboratories around the world by using various instrumental techniques including atomic absorption spectrometry (AAS), inductively coupled plasma atomic emission spectrometry (ICPAES) etc. Although, atomic absorption spectrometry and atomic emission spectrometry are among the most widely methods used for trace metal determination, their sensitivity is usually insufficient for monitoring the low level concentrations of metals in the environmental samples. The interfering effects of the matrix components of the samples are the one of the main problems in the determination of traces heavy metals by AAS and or ICP-AES. Also lower elements concentrations than the detection limits of the instrumental technique are another problem in the trace heavy metal determinations in environmental samples. Consequently, a preconcentration/ separation process is usually required ${ }^{6-10}$.

Coprecipitation ${ }^{11-13}$, membrane filtration ${ }^{14,15}$, electrodeposition ${ }^{16}$, cloud point extraction ${ }^{17}$ and solvent extraction ${ }^{18-21}$ are the popular methods 
for the preconcentration and separation of the traces transition metal ions. Solid phase extraction (SPE) of trace metal ions is also an important preconcentration/separation technique ${ }^{1,22-25}$.

Although, disadvantages such as significant chemical additives, solvent losses, complex equipment, large secondary wastes, unsatisfactory enrichment factors and high time consumption, limit the application of these techniques. These problems could be addressed by the development of modular and compact processes that provide adequate separation and preconcentration without complex processes. The solvent microextraction technique effectively overcomes these difficulties by reducing the amount of organic solvent as well as allowing sample extraction and preconcentration to be done in a single step. The technique is faster and simpler than conventional methods. It is also inexpensive, sensitive and effective for the removal of interfering matrices. Solvent microextraction is a form of solvent extraction with phase ratio values higher than 100 . Compared with the conventional solvent extraction, microextraction may provide poorer analyte recovery, instead the concentration in the organic phase greatly enhances. In addition, the amount of the used organic solvent is highly reduced and only one step

Table 1: Effect of diverse ions on the recovery of $10 \mu \mathrm{g} \mathrm{Cd(II)} \mathrm{in} \mathrm{a} \mathrm{sample}$ volume of $100 \mathrm{MI}$

\begin{tabular}{lcc}
\hline lons & $\begin{array}{c}\text { added } \\
\text { (mg) }\end{array}$ & $\begin{array}{c}\text { (\%)Recovery } \\
\text { of Cd (II) }\end{array}$ \\
\hline $\mathrm{K}^{+}$ & 11 & $90.3(1.3) \mathrm{a}$ \\
$\mathrm{Ca}^{+}$ & 0.02 & $90.6(1.6)$ \\
$\mathrm{Mg}^{+}$ & 1.05 & $90.3(1.9)$ \\
$\mathrm{Na}^{+}$ & 0.11 & $90.4(2.1)$ \\
$\mathrm{Zn}^{+}$ & 1 & $90.5(2.2)$ \\
$\mathrm{Cl}^{-}$ & 0.09 & $90.6(1.8)$ \\
$\mathrm{NO}_{3}^{-}$ & 0.5 & $90.1(2.3)$ \\
$\mathrm{SO}_{4}{ }^{2-}$ & 0.16 & $90.8(2.6)$ \\
$\mathrm{CH}_{3} \mathrm{COO}^{-}$ & 0.1 & $90.2(2.1)$ \\
$\mathrm{Cr}_{2} \mathrm{O}_{7}{ }^{2-}$ & 0.15 & $90.1(1.6)$ \\
\hline
\end{tabular}

a: Values in parenthesis are CVs based on three individual replicate measurements

Table 2: Analytical results for the recovery of $\mathrm{Cd}(\mathrm{II})$ in water samples

\begin{tabular}{lccc}
\hline Sample & $\begin{array}{c}\text { Cd(II) added } \\
(\boldsymbol{\mu g})\end{array}$ & $\begin{array}{c}\text { Found of Cd(II) } \\
\text { with FAAS }(\boldsymbol{\mu g})\end{array}$ & $\begin{array}{c}\text { GF-AAS } \\
(\boldsymbol{\mu g})\end{array}$ \\
\hline Tap Water & 0 & $0.002(1.4)^{\mathrm{a}}$ & $0.003(1.7)$ \\
& 15 & $17.27(1.7)$ & $17.14(1.9)$ \\
& 20 & $23.16(1.3)$ & $22.94(1.6)$ \\
Ground water & 0 & $1.24(1.2)$ & $1.41(1.3)$ \\
& 10 & $21.74(1.1)$ & $21.93(1.2)$ \\
& 20 & $29.83(1.8)$ & $29.78(0.7)$ \\
Waste water & 0 & $3.94(1.8)$ & $3.85(1.7)$ \\
& 5 & $9.63(1.9)$ & $9.74(0.8)$ \\
& 15 & $17.85(1.6)$ & $17.23(1.2)$ \\
$\mathrm{Synthesis} \mathrm{sample}$ & 0 & $\mathrm{~N} . \mathrm{D}^{\mathrm{b}}$ & $\mathrm{N} . \mathrm{D}$ \\
$\mathrm{Ni}^{2+}, \mathrm{Na}^{+} \mathrm{Co}^{2+}$, & 10 & $15.84(1.8)$ & $15.73(0.9)$ \\
$\mathrm{Ba}^{2+}, \mathrm{Ca}^{2+}$ & 20 & $26.57(1.2)$ & $26.46(0.6)$ \\
\hline
\end{tabular}

a: Values in parenthesis are CVs based on three individual replicate measurements

b: Not Detection 
of manipulation is necessary, therefore, problems of contamination and loss of analytes vanishes.

Cloud point extraction (CPE) ${ }^{26-31}$ homogeneous liquid-liquid extraction (HLLE) ${ }^{32,33}$ and single drop microextraction (SDME) ${ }^{34-38}$ are fairly new methods of sample preparation which are used in separation and preconcentration of metals and can solve some of the problems encountered with the conventional pretreatment techniques.

There are a number of literature reports dealing with the preconcentration of $\mathrm{Cd}(\mathrm{II})$ ions based on SPE, most of which employ chelating groups bound to resins or other polymeric supports ${ }^{32-}$ 48. This present work preconcentration of $\mathrm{Cd}^{2+}$ based on the adsorption of its complex on an Multi walled carbon nanotubes carboxylate (MWCNTs-COOH). The adsorbed complex could be eluted using environmentally and the concentration of $\mathrm{Cd}^{2+}$ was determined by FAAS. The influence of various experimental parameters such as acidity, sample volume, flow rate, diverse ions, etc. was examined in detail. The validity of the proposed method was tested in tap water samples and waste water.

\section{EXPERIMENTAL}

\section{Instrumentation}

Determination of $\mathrm{Cd}^{2+}$ by PG-990 flame atomic absorption spectrometer equipped with

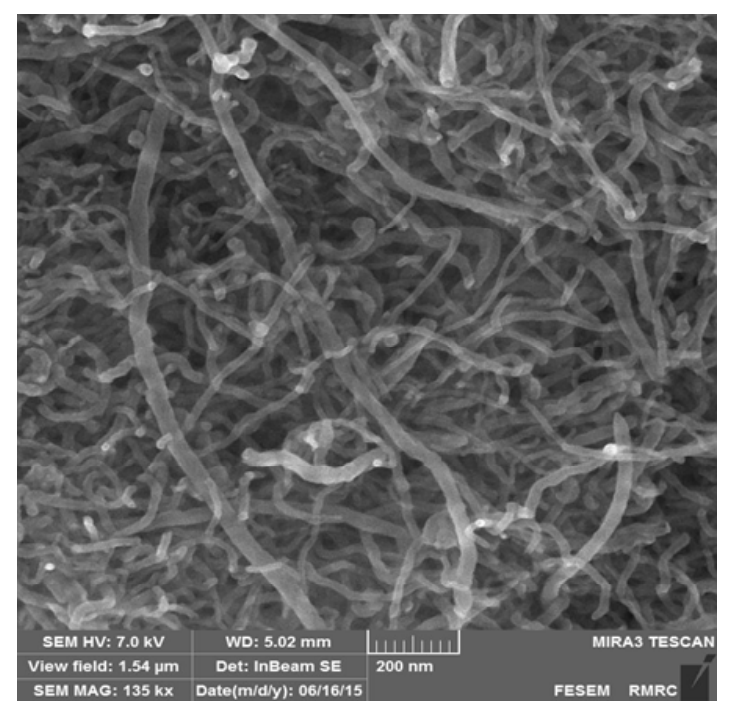

$\mathrm{HI}-\mathrm{HCl}$ according to the recommendations of the manufacturers. These condition are tabulated in ( Table 3). The $\mathrm{pH}$ measurements used by Sartorius model PB-11.

\section{Chemicals and reagents}

Multi walled carbon nanotubes carboxylate (MWCNTs-COOH) were prepared from Darmstadt, Germany of Merck. Method and dried for a week over phosphorus pentoxide in a vacuum desiccators before use. 4-Isocyanatobenzenesulfonyl azide was prepared from 4-carboxybenzenesulfonyl azide via a published procedure ${ }^{17}$. All solutions were prepared with doubly distilled deionized water from Darmstadt, Germany of Merck. $C_{18}$ powder for chromatography with diameter of about $50 \mu \mathrm{m}$ obtained from Katayama Chemicals from Supelco. It was conditioned before use by suspending in $4 \mathrm{M}$ nitric acid for $20 \mathrm{~min}$, and then washed two times with water.

\section{Preparation of Multi walled carbon nanotubes (MWCNTs) cartridge}

A column $1.5 \mathrm{~cm}$ in diameter and $15 \mathrm{~cm}$ in length was used for the preconcentration of $\mathrm{Cd}(\mathrm{II})$. About $5 \mathrm{~g}$ of Multi walled carbon nanotubes cartridge was mixed with $25 \mathrm{~mL}$ of $\mathrm{HCl} 1 \mathrm{M}$ to form slurry and then loaded on to the column. Cotton was placed at the bottom for allowing Multi walled carbon

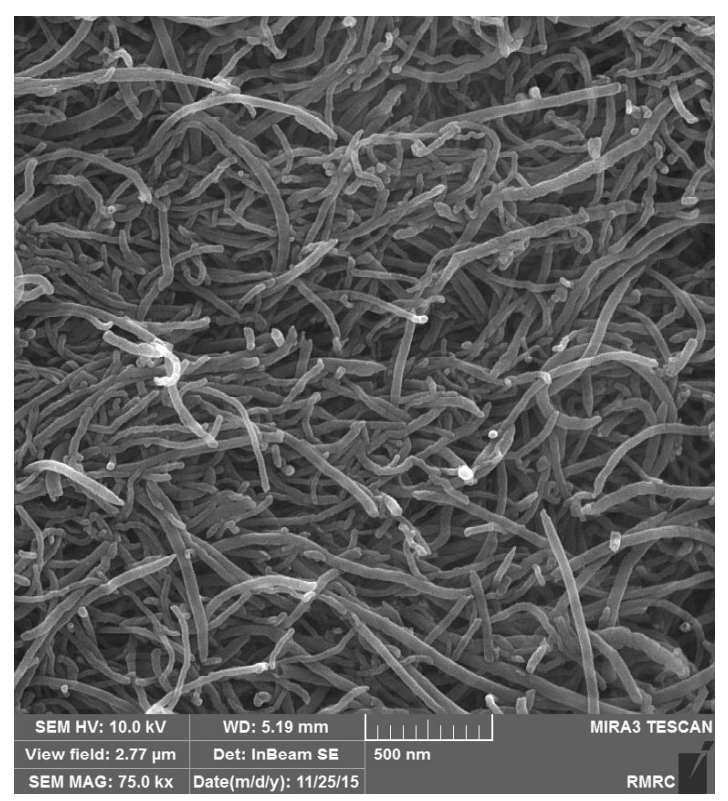

Fig. 1: SEM image of Multi walled carbon nanotubes carboxylate (MWCNTs-COOH) 
nanotubes (MWCNTs) cartridge to settle properly. The column was packed up to a height of $3 \mathrm{~cm}$.

\section{Procedure for present method}

A $50 \mathrm{mg}$ SDS of $50 \mathrm{~mL}$ was loaded on to the column of neutral Multi walled carbon nanotubes (MWCNTs) cartridge maintaining a flow rate of $8 \mathrm{~mL}$

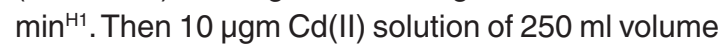
was loaded on to the column. The sample solution was uploading on to the column of neutral Multi walled carbon nanotubes (MWCNTs) cartridge maintaining a flow rate of $0.5 \mathrm{~mL} \mathrm{~min}{ }^{H 1}$. The desorption complex and eluted using $10 \mathrm{~mL}$ of $\mathrm{HNO}_{3} 4 \mathrm{M}$ at a flow rate of $0.5 \mathrm{~mL} \mathrm{~min}^{\mathrm{H} 1}$ and the concentration of $\mathrm{Cd}(\mathrm{II})$ was determined by FAAS.

\section{RESULTS AND DISCUSSION}

Fig.1. show the morphology and size of Multi walled carbon nanotubes (MWCNTs) sorbent as shown in Fig. 1. sorbent retained a homogenous distribution in the range of 156.0-10.0 nm. Fig.2.The formation of MWCNTs was followed by Raman Spectroscopy spectroscopy the carbonyl vibration

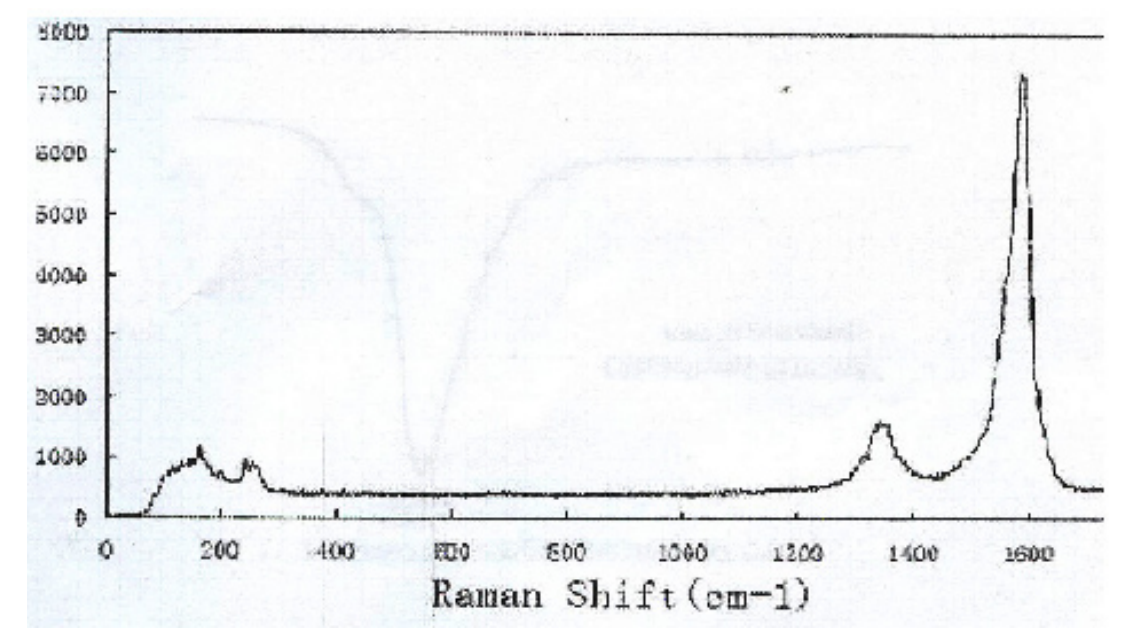

Fig. 2: Raman Spectroscopy image Multi walled carbon nanotubes carboxylate (MWCNTs-COOH)

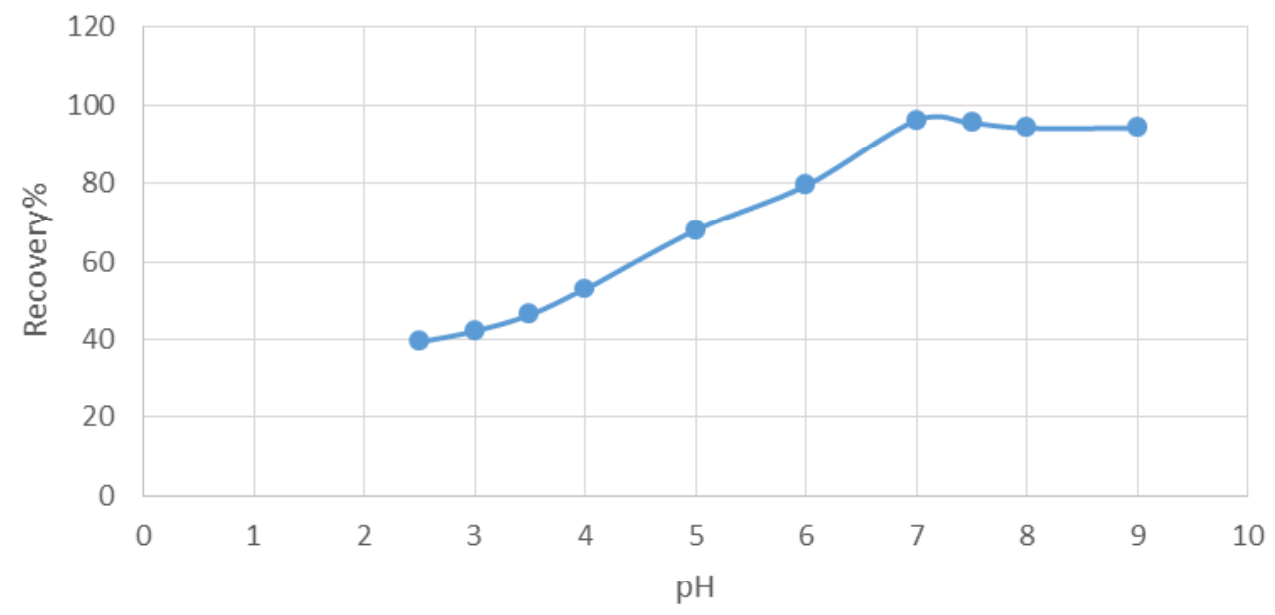

Fig. 3: Extraction percentage of $\mathrm{Cd}(\mathrm{II})$ against pH 
appears at $1580 \mathrm{~cm}^{-1}$, while there are fingerprints at $160 \mathrm{~cm}^{-1}$ and $230 \mathrm{~cm}^{-1}$ due to the presence of hydroxyl species at the carbon nanotubes ${ }^{23}$.

\section{Factor of $\mathbf{p H}$ in Preconcentration}

The factor of $\mathrm{pH}$ of the aqueous solution on the extraction of $100 \mathrm{ng}$ of each of the cations $\mathrm{Cd}(\mathrm{II})$ was studied in the $\mathrm{pH}$ rang of 1-10. The effect $\mathrm{pH}$ of the solution was adjusted by means of either $0.01 \mathrm{M} \mathrm{H} \mathrm{NO}_{3}$ or $0.01 \mathrm{M} \mathrm{NaOH}$. The best of recovery Was obtained indicate that complete chelation and recovery of $\mathrm{Cu}$ (II) occurs in $\mathrm{pH}$ range of 6-8 and that of in 2-9 and are shown in Fig. 3. It is probable that at higher $\mathrm{pH}$ values, the cations might be hydrolysed and complete desorption occur. Hence, $\mathrm{pH}=7.0$ in order to prevent hydrolysis of the cations and also keeping on the cartridge $\mathrm{C}_{18}$, was chosen for further research.

\section{Choice of the eluent}

A reagents were tested in order to desorption complex from the column. In order to choose the most effective eluent for the quantitative recovery of $\mathrm{Cd}(\mathrm{II})$, methanol, ethanol, acetone, $\mathrm{HCl} 1 \mathrm{M}, \mathrm{HCl}$ $3 \mathrm{M}, \mathrm{H}_{3} \mathrm{PO}_{4} 1 \mathrm{M}$, and Acidified solvents obtained by addition of $\mathrm{HNO}_{3} 4 \mathrm{M}$, were studied. The recovery of $\mathrm{Cd}$ (II) was found to be quantitative with ethanol and $\mathrm{HNO}_{3} 4 \mathrm{M}$ as eluting agents. However, $\mathrm{HNO}_{3} 4 \mathrm{M}$ was preferred owing to its non-inflammability and less toxicity ${ }^{16,17}$. It was observed that when the ratio of $\mathrm{HNO}_{3} 4 \mathrm{M}$ a recovery of $99.8 \%$.

\section{Effect of sample volume}

The recovery of the analyte was researched in the range $100-1500 \mathrm{mLmaintaining} \mathrm{an} \mathrm{overall}$ concentration of $0.025 \mathrm{~mol} \mathrm{~L}^{-1}$ sulfuric acid. The resulting complex was eluted using $10 \mathrm{~mL}$ of $\mathrm{HNO}_{3}$

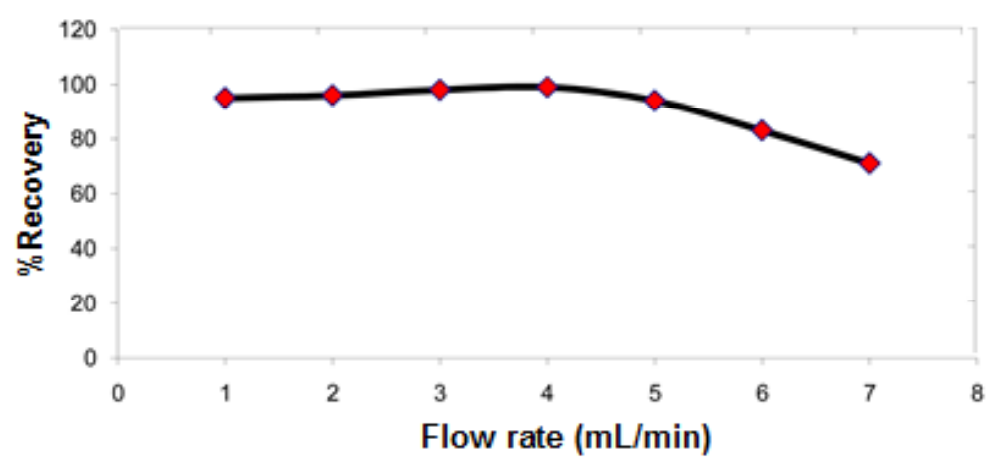

Fig. 4: Effect of flow rates of the sample solutions on the recovery percentage of $\mathrm{Cd}$ (II)

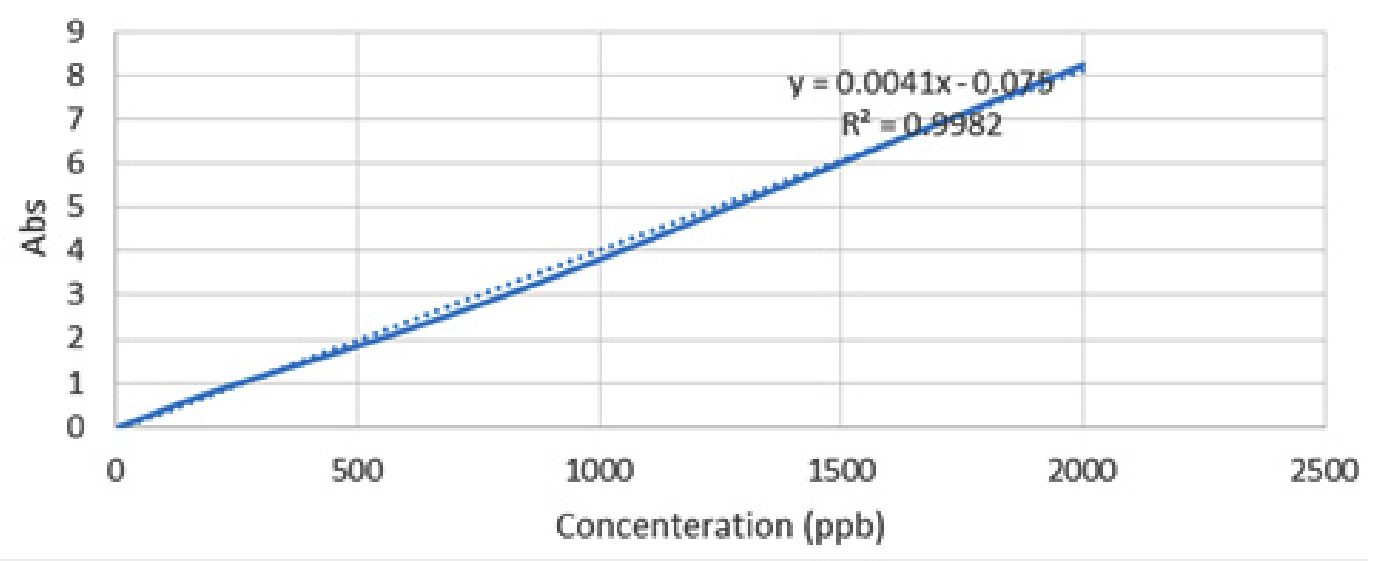

Fig. 5: Calibration curve of $\mathrm{Cd}(\mathrm{II})$ measured by SPE-AAS 
Table 3: The operational conditions of flame for determination of $\mathrm{Cd}$

\begin{tabular}{lc}
\hline Slit width & $0.7 \mathrm{~nm}$ \\
Operation current of HI-HCL & $5.0 \mathrm{~mA}$ \\
Resonance fine & $295.2 \mathrm{~nm}$ \\
Type of background correction & Deuterium lamp \\
Type of flame & Air/acetylene \\
Air flow & $9.0 \mathrm{~mL} \cdot \mathrm{min}^{-1}$ \\
Acetylene flow & $2.7 \mathrm{~mL} \cdot \mathrm{min}^{-1}$ \\
\hline
\end{tabular}

$4 \mathrm{M}$. As can be seen from the figure, it is evident that the recovery of $\mathrm{Cd}(\mathrm{II})$ is more than $97 \%$ up to $250 \mathrm{~mL}$ sample volume. A preconcentration factor of 57 could be attained for more than $97 \%$ of $\mathrm{Cd}(\mathrm{II})$ when the sample volume was $250 \mathrm{~mL}$.

\section{Effect of flow rate}

The flow rate suitable for optimum loading of $\mathrm{Cd}(\mathrm{II})$ complex on the Multi walled carbon nanotubes carboxylate (MWCNTs-COOH) cartridge. This could be probably due to the insufficient contact time between the sample solution and Multi walled carbon nanotubes carboxylate (MWCNTs- $\mathrm{COOH}$ ) cartridge. A flow rate of $5 \mathrm{~mL} \min ^{11}$ was maintained for the elution of $\mathrm{Cd}(\mathrm{II}) \mathrm{Fig} 4$.

\section{Precision studies and limit of detection}

Under optimized conditions, a calibration curve for Cd (II) was found by preconcentrating a series of $\mathrm{Cd}$ (II) standards according to the procedure mentioned. The curve was linear from $1.0 \mathrm{mg} / \mathrm{l}$ to 7.0 $\mathrm{mg} / \mathrm{l}$ for $\mathrm{Cd}$. As analytical figures of merit, The limit of detection was found to be $0.07 \mu \mathrm{g} \cdot \mathrm{mL}^{-1}$.

\section{Effect of foreign ions ions}

The influence of common foreign ions on the adsorption of $\mathrm{Cd}$ (II) on Multi walled carbon nanotubes carboxylate (MWCNTs- $\mathrm{COOH}$ ) were studied. In these work, $50.0 \mathrm{ml}$ solutions containing $5 \mathrm{ppm}$ of $\mathrm{Cd}$ and various amounts of interfering ions were treated according to the suggested procedure. The tolerance level was defined as the maximum concentration of the foreign ion causing a change in the analytical signal no higher than $5 \%$, when compared with the signal of 5ppm copper alone. The results, listed in Table 1 demonstration that the presence of major cations and anions in natural water has no important influence on the adsorption of $\mathrm{Cd}$ (II) ions under the designated conditions.

\section{Recovery studies in real sample}

The accuracy of the proposed method was tested by spiking known concentrations of copper(II) to tap water(Tehran, taken after 10 min operation of the tap), and rain water (Tehran, 21 Jun, 2016) samples. The water samples were filtered and stored in PET bottles. The recovery of Copper(II) was found to be satisfactory with a relative standard deviation of $5 \%$ for 3 replicate measurements and the results are shown in Table 2.

\section{Comparison with other solid phase adsorbents}

The present method was compared to a variety of solid adsorbents reported recently in the literature. Also, the proposed method was free of interference compared to conventional procedures to determine $\mathrm{Cd}(\mathrm{II})^{49-51}$. As can be seen from the references, it is evident that the preconcentration factor obtained with Multi walled carbon nanotubes carboxylate (MWCNTs- $\mathrm{COOH}$ ) cartridge is comparable to or even better than most of the other chelating matrices. The significant feature of the proposed method is the use of water samples benign $\mathrm{HNO}_{3} 4 \mathrm{M}$ for the elution of the complex.

\section{Calibration curve}

The calibration curve of $\mathrm{Cd}$ (II) solutions is represented in Fig. 5 and the related regression is $\mathrm{Y}=0.0041 \mathrm{X}+0.075$ providing a correlation coefficient of $R^{2}=0.9982$.

\section{CONCLUSIONS}

The proposed SPE method possesses advantages such as easiness, and considerable selectivity in comparison with the previously reported procedures for isolation and determination of $\mathrm{Cd}^{2+}$ contents ${ }^{49,50,51}$. The highest preconcentration factor attainable was 57 for a $250 \mathrm{mLsample}$ volume. In conclusion, the proposed SPE possesses the following advantages: the technique is rapid when compared with the previously reported procedures for the separation and determination of $\mathrm{Cd}^{2+}$, the time taken for the separation and determination of copper in a $500 \mathrm{~mL}$ sample is at the most 30 min. Furthermore, it is a simple, highly sensitive, selective and reproducible method for the separation of $\mathrm{Cd}^{2+}$ and in this work the recovery yields obtained with Multi walled carbon nanotubes carboxylate (MWCNTs-COOH)were about $95-100 \%$ then it 
show derivation e.g. in this work Multi walled carbon nanotubes carboxylate (MWCNTs-COOH) is full of potential for use as a adsorbent in the extraction method like SPE and SPME .consequently it can be applied to the preconcentration and determination of $\mathrm{Cd}^{2+}$ and the large number of heavy metal that are dangers for human from real samples.

\section{ACKNOWLEDGMENTS}

We gratefully acknowledge financial of department of chemistry, department of Varamin branch Islamic Azad University for financial support.

\section{REFERENCES}

1. De Alc^antara I.L, Roldan P.S.,. Margionte M.A.L,. Castroa G.R, Padilha C.C.F., Florentino A.O., Padilha P.M., J. Braz. Chem. Soc. 2004 ., 15 .,366-371.

2. H.W., Qian Y., Kong X.T., Xia S.Q., , Instrum. Sci. Technol. 2004., 32 .,195-205.

3. Tan-Kristanto A., Hoffmann A., Woods R., Batterham P., Cobbett C., C. Sinclair,Arabidopsis thaliana, New Phytol. 2003., 159 .,471-477.

4. Viard B., Pihan F., Promeyrat S., Pihan J.C., Chemosphere 2004., 55 .,1349-1359.

5. Akba O.,. Baysal A, Hamamci C., Merdivan M., Gumgum B., Fresen. Environ.Bull. 2003., 12, 1412-1415.

6. Nwosu F.O., Adekola F.A., Ibitoye E., Bull. Chem. Soc. Ethiopia $17(1)$ 1-9.

7. Ferreira A.C., Costa A.C.S., Korn M.G.A., Brazil, Microchem. J. 2004 78 .,77-83.

8. Hadjar H., Hamdi B., Kessaissia Z., Desalination 2004., 167, 165-174.

9. Kiptoo J.K, Ngila J.C., Sawula G.M., Talanta 2004., 64, 54-59.

10. Minamisawa H., lizima S., Minamisawa M., Tanaka S., Arai N., Shibukawa M., Anal. Sci. 2004., 20 .,683-697.

11. Krishna P.G, Gladis J.M., Rambabu U., Rao T.P., Naidu G.R.K., Talanta 2004.,63, 541-546.

12. Wang L., Hu B., Jiang Z., Li Z., Int. J. Environ. Anal. Chem. 2002., 82., 387-393.

13. Tokman N., Akman S., Bakircioglu Y., Microchim. Acta 2004., 146 .,31-34.

14. Soylak M., Narin I., Divrikli U., Saracoglu S., Elci L., Dogan M., Anal. Lett. ., 37, 767-780.

15. M.D. Granado-Castro, M.D. Galindo-Ria no, M. Garc'ýa-Vargas, Spectrochim.Acta: Part B
2004.,59 577-583.

16. He H.B., Zhang W.J., Ma G.Z., Shen H.X., hinese J. Anal. Chem. 2001.,29 (10) 11251128.

17. Paleologos E.K, Stalikas C.D., TzouwaraKarayanni S.M., Karayannis M.I., Anal. Chim. Acta 2001., 436 .,49-57.

18. Camino M.,. Bagur M.G, Sanchez-Vinas M., Gazquez D., Romero R.,J. Anal. Atom. Spectrom. 2001, 16.,638-642.

19. Khuhawar M.Y., Lanjwani S.N., J. Chem. Soc. Pakistan.,2001., 23 157-162.

20. Tautkus S., Steponeniene L., Kazlauskas R., J. Serb. Chem. Soc. 2004., 69 .,393-402.

21. Tautkus S., Chem. Anal. (Warsaw) 2004., 49 .,271-276.

22. Moghimi A. ,Chinese Journal of Chemistry, 2007, 25, 640 .

23. Moghimi A, "Chinese Journal of Chemistry" 2007, 25, 10, 1536.

24. Moghimi A, Shahryar Ghammamy "Environmental chemistry an Indian journal'2007, 2, 3

25. Moghimi A Orient. J. Chem.2006,22(3),527.

26. Hinze, W.L.; Pramaur, E.; Rev. Crit. ; Anal. Chem. 1993, $24,133$.

27. Moghimi A, Afr J Pure Appl Chem. 2013,7(2), 79-90.

28. Paleogos, E.K. ; Giokas, D.L. ; Karayannis, M.I.. ; Trends Anal. Chem. 2005, 24, 426.

29. Borges, D.L.G. ; daVeiga, M.A.M.S. ; Frescura, V.L.A. ; Welz, B.; Curtius, A.J. J. Anal. At. Spectrom. 2003, 18,501 .

30. Nayebi P.,; Moghimi A. , Orient. J. Chem.2006,22(3),507.

31. Zhu, X. ; Zhu, X. ; Wang, B. ; Microchim. Acta 2006, 154, 95.

32. Ghiasvand, A.R. ; Shadabi, S. ; 
Mohagheghzadeh, E. ; Hashemi, P. ; Talanta 2005,66,912.

32. Sekido E., Chayama K., Muroi M., Talanta $1985,32,797$.

33. Que M., Kimura K., Shano T., Anal. Chim. Acta 1987,94,293.

34. Kolthoff I.M.,. Chantooni M.K, J. Chem. Eng. Data 1993,38,556.

35. Majors R.E., LC-GC 1989,4,972.

36. Moors M.,. Massart U.L,. Dowall R.D.M.C, Pure Appl. Chem. 1994, 66,277.

37. Taylor K.Z., Waddell D.S., E.J. Macpheson, Analytica 1993,67,1186.

38. Yamini Y., Ashraf-Khorasani M., High Resolut. Chromatogr. 1997, 17, 634.

39. Yamini Y., Shamsipur M., Talanta 1996,43,2117.

40. Bjorklund L.B., Morrison G.M., Anal. Chim. Acta 1997,343,259.

41. Yamini Y., Alizadeh N., Shamsipur M., Anal. Chim. Acta 1997,355,69.
42. Raoufi F., Yamini Y., Sharghi H., Shamsipur M., Microchem. J. 1999, 63,311.

43. Shamsipur M., Ghiasvand A.R., Yamini Y., Anal. Chem. 1999, 71,4892.

44. Taher M.A.,. Puri S, Bansal R.K., Puri B.K., Talanta.,1997.,45 .,411-416.

45. Shemirani F., Abkenar S.D., J. Anal. Chem. 2004., 59 (4) 327-330.

46. Taher M.A., Turk. J. Chem.2003.,. 27 529537.

47. Manzoori J.L,. Karim-Nezhad G, Anal. Sci. 2003., 19 (4) 579-583.

48. Bermejo-Barrera P., Nancy M.A., Cristina D.L., Adela B.B., Microchim.Acta 2003., 142 (1-2) 101-108.

49. Moghimi Ali; Orient. J. Chem. 2006, 22(3),527.

50. Moghimi Ali.; Ghammamy S. "Environmental chemistry an Indian journal'2007,.2,,3.

51. Choi,Y.S.;Choi,H.S.Bull.Korean Chem. Soc. 2003.,24.,222. 